and costly task for Croatia's healthcare system and represents an important local advance in monitoring the population's health. Its results must be fully used to improve the population's health.

Contributors and sources: JK conceived and designed the study, analysed and interpreted the data, and drafted and revised the article. MS conceived and designed the study, interpreted the data, and revised the article. TC revised the article, SV conceived and designed the study, analysed and interpreted the data, and drafted and revised the article. JK, MS, and TC did the literature search. JK is the guarantor.

Funding: Croatian Ministry of Health, Health System Project IBRD (loan 4513-0 HR).

Competing interests: None declared.

Ethical approval: Not required.
Croatian Central Bureau of Statistics. Statistical yearbook 2004. Zagreb: Croatian Central Bureau of Statistics, 2004. (DEM-2/03.)

2 McKee M, Fister K. Post-communist transition and health in Europe. BMJ 2004;329:1355-6.

3 Kern J, Ivankovic D, Sogoric S, Vuletic S. What was the lifestyle of people who died by cardiovascular diseases? Med Arh 2004;58:351-3.

Bautista MC, Engler MM. The Mediterranean diet: is it cardioprotective? Prog Cardiovasc Nurs 2005;20(2):70-6.

5 Trichopoulou A, Bamia C, Trichopoulos D. Mediterranean diet and survival among patients with coronary heart disease in Greece. Arch Intern Med 2005;165:929-35.

6 Trichopoulou A, Orfanos P, Norat T, Bueno-de-Mesquita B, Ocke MC, Peeters PH, et al. Modified Mediterranean diet and survival: EPIC-elderly prospective cohort study. BMJ 2005;330:991.

7 Béland Y, Bailie L, Page J. Statistics Canada, Croatian Ministry of Health, and Central Bureau of Statistics: a joint effort in implementing the 2003 Croatian adult health survey. Toronto: American Statistical Association, 2004. (Proceedings of the American Statistical Association Meeting on survey research methods, 2004.)

\title{
Public health reforms in Estonia: impact on the health of the population
}

\author{
Kaja Põlluste, Georg Männik, Runo Axelsson
}

Department of Public Health, University of Tartu, Ravila 19, 50411

Tartu, Estonia Kaja Põlluste assistant professor of health care management ERGO Insurance Co, Estonia Georg Männik member of managing board

Nordic School of Public Health, Gothenburg, Sweden

Runo Axelsson professor of health management

Correspondence to: K Põlluste

kaja.polluste@ut.ee

BMJ 2005;331:210-3
The health of the population has worsened in most countries in central and eastern Europe during the transition period, but little has been written about the reforms in the field of public health during this time, and little evidence has been presented on the links between these reforms and the health of the population.

We describe public health reforms in Estonia, focusing on the institutional structure, the reform rationale, the specific proposals and reform processes, the achievements and limitations, and the wider impact of the reforms. ${ }^{1}$ To describe trends in the health of the population, we use life expectancy, infant mortality, rate of abortions per 100 live births, morbidity rates (tuberculosis, HIV, sexually transmitted diseases), and the level of individual risk factors (smoking, diet, alcohol consumption). The study is based mainly on an analysis of previously published reports and official statistics.

\section{Institutional structure}

After the political changes in the beginning of the 1990s, the importance of a population based approach to public health was recognised in Estonia, and the understanding and application of the concept of health promotion became more comprehensive. ${ }^{2-4}$

In 1993 the Ministry of Social Affairs was established and included a Department of Public Health (fig 1, box 1), which was seen as a source of modern health promotion in Estonia. Health promotion was introduced in the curriculum of medical and nursing training at the University of Tartu, and public health training for civil servants and teaching staff was started. $^{45}$

\section{The reform rationale}

In general, democracy is considered to be good for the health of the population. ${ }^{6}$ When starting to build up a democratic society in the beginning of the $1990 \mathrm{~s}$, Estonia, like most other countries in central and eastern Europe, experienced a rapid worsening in population

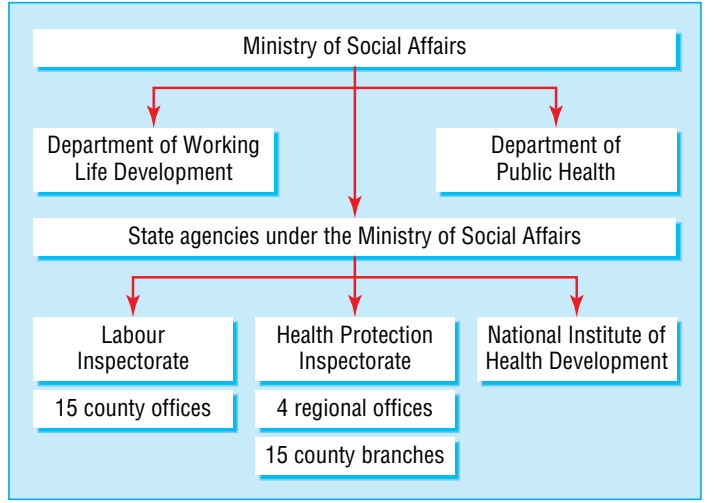

Fig 1 Organisation of health services in Estonia

health indicators. From 1988 to 1994, the life expectancy of males decreased by 5.5 years, due mostly to increased mortality in men of working age. The average life expectancy of men and women showed a big difference.

In 1994, $56 \%$ of the male population died before the age of 65 . Most of these deaths were caused by external factors, particularly at younger ages, where injuries, poisonings, homicides, and suicides made up about three quarters of the causes of death. ${ }^{7}$ Compared with Sweden, for example, the injury death rate for men was about six times higher, and for some types of injuries, such as alcohol intoxication and homicide, death rates were 10 times higher. ${ }^{8}$

Another serious public health problem since the beginning of the 1990 s has been the continual increase in new cases of tuberculosis, ${ }^{7}$ especially multi-drug resistant tuberculosis. About half of these patients are alcohol misusers, but homeless and poor people are also at great risk. ${ }^{9}$

Reproductive health and sexual behaviour in the first half of the 1990s was described by high numbers of

General information about Estonia is on bmi.com 
abortions and a growth of new cases of sexually transmitted diseases (table). ${ }^{7}$ The number of smokers and high consumers of alcohol started to increase in 1990 (see figs 2 and 3). ${ }^{10}$ The weekly consumption of alcohol in Estonia was significantly higher among both men and women in Estonia than in the other Baltic countries. ${ }^{11}$

\section{The reform proposals and processes}

In 1995, the Ministry of Social Affairs formulated an Estonian health policy, which was approved by the government. This document defined the main factors influencing health and the necessary courses of actions, but action was delayed by changes in the government. ${ }^{3}$ Responsibilities in human health protection, disease prevention, and health promotion were defined in the Public Health Act of 1995.

A major landmark in the public health reforms was the Estonian Health Project (1995-9). ${ }^{12}$ It was financed by the World Bank to support the health reform efforts initiated by the government. As a prerequisite for that project, the Ministry of Social Affairs had to agree to carry out nationwide programmes in prevention of cardiovascular diseases and injuries, family planning, and anti-smoking.

The first national health programme on HIV was initiated in 1992. In the middle of the 1990s, three other national health programmes were launched and are continuing (box 2). Several national health projects have been initiated in certain priority areas. Since 1995, national as well as local health promotion projects have been financed by the the Estonian Health Insurance Fund.

\section{Achievements and limitations}

Most of the activities in the field of health promotion started in the period $1993-5$, and in the 10 years since then the health status of the population has changed. Life expectancy for both men and women has increased, and infant mortality per 1000 live births has decreased considerably. The rate of abortions has declined since 1992 (table)..$^{13} 14$

Since 2001, the number of new cases of tuberculosis has begun to decrease, as has the incidence of sexu-

\section{Box 1: Organisation of public health services in Estonia}

\section{Ministry of Social Affairs}

Created in 1993 by merging the former Ministries of Health, Social Welfare, and Labour. Two departments are responsible for the development of public health policy:

Department of Public Health-responsible for health promotion and disease prevention, environmental health, and communicable disease control. Department of Working Life Development-responsible for occupational health and safety issues.

\section{State agencies under the Ministry of Social Affairs}

Health Protection Inspectorate-a successor of the Soviet sanitary-epidemiological service and up to 1993 responsible for implementing prevention and health education. It is responsible for the surveillance and control of communicable diseases and environmental health hazards, implementation of the national immunisation programme, and development of the environmental health information system Labour Inspectorate-responsible for the surveillance and control of occupational health and safety

National Institute of Health Development-established in 2003 by merging three smaller governmental institutions. It is responsible for coordinating national public health programmes and most of the national health promotion projects, but also for the applied research and analysis in public health, continuing professional training in public health, and public health monitoring and reporting

National Centre of Health Promotion and Education-established in 1993 as an independent structure within the Ministry of Social Affairs. Until 2003,

when it was incorporated in the National Institute of Health Development, it was responsible for coordinating most national health programmes and health promotion projects at national level. In the middle of the 1990s the centre introduced a system of health promotion specialists working at county government level, which created a good foundation for a community based public health organisation, and trained these specialists.

\section{Estonian Health Insurance Fund}

The fund provides financing for national disease prevention activities (screening programmes) and supports health promotion activities. Since $1995,0.5-1 \%$ of the health insurance budget has been spent on funding health promotion projects every year. Since 2001 the health promotion budget has not increased. This funding is open to anyone, and applications for projects are evaluated by an advisory committee at the fund. From 2005, the funding of health promotion projects is subject to public tender.

ally transmitted diseases. However, in 2000 and 2001, an explosive increase of new cases of HIV infection became a serious public health problem (table).

Individual risk factors have also changed, particularly the dietary habits of the Estonian population. The

Selected health indicators, Estonia

\begin{tabular}{|c|c|c|c|c|}
\hline Health indicator & 1990 & 1994 & 2002 & 2004 \\
\hline \multicolumn{5}{|l|}{ Life expectancy (years): } \\
\hline Males & 64.6 & 61.2 & 65.2 & NA \\
\hline Females & 74.6 & 73.1 & 77.0 & NA \\
\hline Infant mortality (per 1000 live births): & 12.3 & 14.4 & 5.7 & NA \\
\hline Early neonatal deaths (0-6 days) & 6.1 & 6.6 & 2.4 & NA \\
\hline Neonatal deaths (0-4 weeks) & 8.0 & 9.5 & 3.6 & NA \\
\hline Post-neonatal deaths (4 weeks-1 year) & 4.3 & 4.9 & 2.1 & NA \\
\hline Number of abortions per 100 live births & 132.0 & 160.2 & 101.3 & NA \\
\hline \multicolumn{5}{|l|}{ Morbidity (incidence per 100000 population): } \\
\hline Tuberculosis & 21.0 & 35.0 & 38.4 & 31.6 \\
\hline Syphilis & 3.3 & 56.5 & 20.1 & 13.6 \\
\hline Gonorrhoea & 128.0 & 205.0 & 39.7 & 38.3 \\
\hline HIV infections & 0.5 & 0.7 & 66.2 & 54.8 \\
\hline \multicolumn{5}{|l|}{ Type of cooking fat ( $\%$ of households): } \\
\hline Vegetable oil & 21.5 & 64.5 & 89.0 & NA \\
\hline Animal fat & 26.1 & 15.9 & 3.4 & NA \\
\hline Butter, margarine, vegetable fat, or mixture & 52.4 & 19.6 & 7.6 & NA \\
\hline Use of fresh vegetables at least three times per week among the adult population (\%) & 27.5 & 34.3 & 50.3 & NA \\
\hline
\end{tabular}

$\mathrm{NA}=$ not available. 


\section{Box 2: National health programmes and projects in Estonia}

\section{Programmes initiated since 1992}

National Preventive Programme for HIV/AIDS (1992)-main objective is to decrease HIV/AIDS infections through information, training, and campaigns National Children and Adolescents Health Programme (1996)-main objective is to improve children's health and quality of life by injury prevention, promotion of mental health, and improvement of school environment and nutrition National Programme for Drug and Alcohol Prevention (1997)-main objective is to slow down the growth of drug use by $20 \%$ by the year 2007 , and to reduce hospitalisation of patients with alcohol psychosis by 10\% by the year 2007 National Programme for Prevention and Cure of Tuberculosis (1998)-objectives are to reduce tuberculosis incidence to the level of maximum 30 new cases per 100000 of the population by year 2005, and to protect the population from tuberculosis infection and prevent the development of drug resistance

\section{Projects initiated since 1993}

Heart Health Project (1993)-main objective is to prevent early morbidity and mortality from cardiovascular diseases by informing and educating the population and creating an environment supporting health Anti-Smoking Project (1996)-main objectives are to decrease smoking in the population, help people to quit smoking, and prevent young people from starting smoking

Injury Prevention Project (1993)-main objective is to decrease the number of injuries and deaths caused by road traffic crashes

Family Planning Project (1995)-focused on young people, with the main objective of improving the population's sexual and reproductive health

use of vegetable oil has increased and the use of animal fat has decreased. Another positive change is a higher consumption of fresh vegetables (table). ${ }^{10} 1516$

The proportion of daily smokers, both male and female, grew rapidly until 1994 and has not shown any clear tendency to decrease since then (fig 2). A similar trend has been observed concerning the consumption of alcohol (fig 3). ${ }^{1015} 16$

\section{Impact of reforms}

Every health reform should be focused on better health outcomes for the population. ${ }^{17}$ However, the moving forces of reforms are often economic and political, especially in the field of public health, where the outcomes depend on the cooperation of different sectors of society. The health of the population is also related to economic and political processes in society. ${ }^{18} 19$

The decrease in life expectancy and the increase of mortality due to diseases of the circulatory system and external causes has mainly affected the social groups

\section{Summary points}

The national health programmes and projects initiated in Estonia in the middle of the 1990s have had a positive impact on the health of the population, as shown in improvements in life expectancy, infant mortality, number of abortions, sexually transmitted diseases, and dietary choices

Some health indicators have not improved, notably the incidence of HIV infection

Public health reforms have to be supported by political decisions that make it easier for people to make healthy choices

Priority setting, expressed in a clearly stated health policy and strategy, is needed

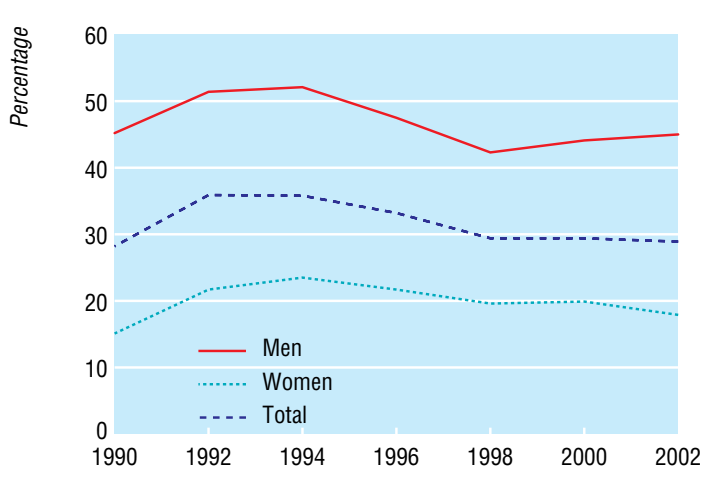

Year

Fig 2 Percentage of adults who smoke daily, Estonia, 1990-2002

that have experienced the most socioeconomic difficulties during the transition period: those who were less educated and had a lack of social support. ${ }^{9112021}$ The health projects have focused on raising the awareness of the population and changing their attitudes towards healthier choices, without considering socioeconomic risk factors such as unemployment or poverty in specific target groups.

More progress in improving the health of the population has been made when the surrounding environment has been supportive. For example, the positive trends in dietary habits started after the monetary reform in 1992, when the range of goods in the shops changed dramatically and people got a chance to make healthier choices. The decrease in the number of abortions and in the incidence of sexually transmitted diseases is believed to have occurred because of raised awareness in the population, along with better availability of contraception.

Regardless of intensive health promoting activities, progress in reducing alcohol consumption and tobacco smoking has been unremarkable. This illustrates how health promotion is ineffective unless it is supported by other social and economic policies. Alcohol and tobacco policy in Estonia has been liberal, and alcohol and tobacco products are inexpensive and easily accessible.

Health programmes and projects need to have clearly formulated objectives and a well defined strategy to achieve expected results. A good example is the National Programme for Prevention and Cure of Tuberculosis, which has almost achieved one of its objectives, to decrease the number of new cases to 30 per 100000 inhabitants. At the same time, however, the HIV prevention programme has had no positive effects. There has been very little collaboration between the different sectors involved, and the objectives and the strategy of the programme were not clearly formulated.

\section{Conclusions}

During the past decade, Estonia has made some progress in public health. Several national programmes dealing with essential health risks have been initiated and financed by the state budget, and the Estonian Health Insurance Fund has contributed by earmarking resources for health promotion projects. 


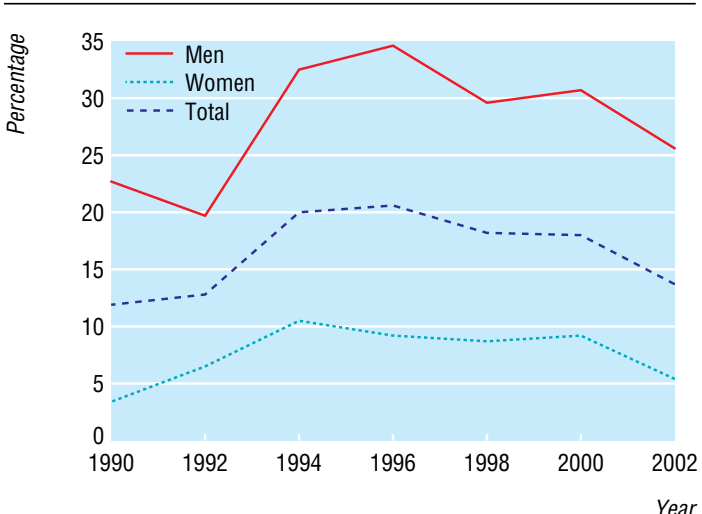

Fig 3 Percentage of adults who drink spirits every week, Estonia, 1990-2002

As a result, there is some evidence of a positive impact on the health of the population, but some health indicators have not improved.

To be effective, public health reforms must be supported by political decisions that make it easier for people to make healthy choices. A comprehensive national health policy and strategy is still lacking in Estonia. The evaluation of the health programmes and projects is often complicated because the objectives have not been clearly formulated and lack measurable targets. Priority setting expressed in a clearly stated health policy and strategy is needed. The strategy should be evaluated systematically to find the most effective way to improve the population's health.

Contributors and sources: KP is assistant professor of health care management at the University of Tartu in Estonia and doctoral student at the Nordic School of Public Health in Sweden. She is preparing a doctoral thesis on health system development in Estonia. GM is currently a member of the managing board of the ERGO life and non-life insurance company in Estonia, Latvia, and Lithuania. He has worked in the field of social insurance and welfare in Estonia, and as a consultant on social policy in different countries in central and eastern Europe. RA is professor of health management at the Nordic School of Public Health in Sweden. He has also worked as an expert for the European Union in different countries in central and eastern Europe countries. The idea of this article was developed and a first draft written by KP after revisiting previous studies and health statistics. The subsequent drafts and the final draft was jointly written by all authors. KP is guarantor.

Funding: None.

Competing interests: None declared.

Gonzales Block MA. Comparative research and analysis methods for shared learning from health system reforms. Health Policy 1997;42:187209.

2 Public health and family medicine. WHO/World Bank seminar 28-29 November 1994, University of Tartu, Estonia. Tartu: Trükiekspert Ltd, 1994.

3 Estonian Centre for Health Education and Promotion. Health promotion in Estonia. Tallinn: Estonian Centre for Health Education and Promotion, 1996.

4 Saava A. History of public health research in Estonia. Eur J Public Health 2000;10:64-7.

5 Köhler L, Eklund L. BRIMHEALTH. A successful experience in NordicBaltic cooperation in public health training. Eur J Public Health 2002; 12:152-4.

6 McKee M, Nolte E. Lessons from health during the transition from communism. BMJ 2004;329:1428-9.

7 Põlluste K, ed. Public health in Estonia. Tartu: Elmatar Publishing House, 1998.

8 Kaasik T, Andersson R, Horte LG. The effects of political and economic transitions on health and safety in Estonia: an Estonian-Swedish comparative study. Soc Sci Med 1998;47:1589-99.

9 Lindsay M. Estonia races to halt multidrug-resistant TB before HIV takes hold. Bull World Health Organ 2002,80:519.

10 Lipand A, Kasmel A, Tasa E, Leinsalu M, Uutela A, Puska P, et al. Health behaviour among Estonian adult population, spring 1994. Helsinki: National Public Health Institute, 1995. (B5/1995.)

11 McKee M, Pomerleau J, Robertson A, Pudule I, Grinberga D, Kadziauskiene K, et al. Alcohol consumption in the Baltic Republics.J Epidemiol Community Health 2000;54:361-6.

12 World Bank. Staff appraisal report, Estonia, health project. Washington: World Bank, 1995. (Report No. 13297-EE.)

13 Ministry of Social Affairs. Estonian Health Statistics 1992-1999. Tallinn: Ministry of Social Affairs of Estonia, 2000.

14 Ministry of Social Affairs. Estomian Health Statistics 2000-2002. Tallinn: Ministry of Social Affairs of Estonia. 2003 .

15 Lipand A, Kasmel A, Kivilo M, Tasa E, Berg M-A, Peltoniemi J, et al. Health behaviour among Estomian adult population, spring 1990. Helsinki: National Public Health Institute, 1992. (B1/1992.)

16 Kasmel A, Lipand A, Markina A. Health behaviour among Estonian adult population, spring 2002. Tallinn: Estonian Centre for Health Education and Promotion, 2003.

17 Saltman RB, Busse R, Mossialos E, eds. Regulating entrepreneurial behaviour in European health care systems. Buckingham: Open University Press, 2002 (European Observatory on Health Care Systems series)

18 Liu Y, Rao K, Fei J.Economic transition and health transition: comparing China and Russia. Health Policy 1998:44:103-22.

19 Värnik A, Kõlves K, Wasserman D. Suicide among Russians in Estonia: Värnik A, Kõlves K, Wasserman D. Suicide among Russians in Esto

20 McKee M, Shkolnikov V. Understanding the toll of premature death among men in Eastern Europe. BMJ 2001;323:1051-5.

21 Leinsalu M, Vagero D, Kunst AE. Estonia 1989-2000: enormous increase in mortality differences by education. Int J Epidemiol 2003;32:1081-7.

\title{
Transition and public health in the Slovak republic
}

\author{
Gabriel Gulis, Jarmila Korcova, Peter Letanovsky, Daniela Marcinkova
}

The socioeconomic and environmental changes arising from transition have affected public health. Improvement has started but there is still a long way to go

Like other Central and Eastern European countries, the Slovak Republic is in transition from a directive, centralised, political system to a democratic, market economy based system. However, since the break-up of the former Czechoslovakia on 1 January 1993, the republic is also undergoing transition from the federal system of policy making and leadership to an independent sovereign state (infrastructural transition). The development of a fully independent health sector within the Slovak Republic has posed serious challenges for public health policy makers and practi- tioners. We describe the main steps and changes during transition and discuss the achievements and tasks ahead.

\section{Legislative reform}

In 1994, an update of the act for the protection of human health restructured the public health system. Responsibility was delegated to the Ministry of Health, the main hygienist of the Slovak Republic, and regional hygienists. The National Office of Public Health currently has 36 regional offices. A new public
Unit of Health Promotion Research Institute of Public Health, University of Southern Denmark, Niels Bohrsvej 9-10, 6700 Esbjerg, Denmark

Gabriel Gulis associate professor continued over BMJ 2005;331:213-5 